\title{
Optimization of Rotational Speed in the Growing of the Thin Film Using Sol Gel Method which is Prepared with Spin Coating
}

Yofentina $\mathrm{I}^{1 *}$, Viska IV1, Hikam $\mathbf{M}^{2}$, Bambang $\mathrm{S}^{2}$, Alfan $\mathbf{M}^{1}$ and Wahyu $\mathbf{P}^{1}$

${ }^{1}$ Jurusan Fisika FMIPA, Universitas Sebelas Maret, Jl. Ir. Sutami 36A Surakarta, Indonesia

${ }^{2}$ Departemen Fisika FMIPA, Universitas Indonesia, Depok, Indonesia

\begin{abstract}
We investigated the effects of the rotational speed in the spin coating process for growing the BZT thin film. In this process, the rotational speed is taken to be $2000 \mathrm{rpm}, 3000 \mathrm{rpm}$ and $4000 \mathrm{rpm}$ while the number of layer is kept constant in five layers. We also discuss the effect of the layers number in the growing of the BZT thin films. For this purpose, we take the layers number to 5, 10 and 15 layers and take the constant rotational speed of 4000 rpm. In order to characterize the formed BZT thin film, the composition, crystal structure and morphological tests are performed. We found that the increasing of the rotational speed then the deposited material in the Si substrate is decreased. As a result, the X-ray intensity in certain orientation is also decreased which is indicates that the probability to form the crystal in a certain orientation is influenced by deposited material in the Si substrate. The measured grains size of the BZT thin film almost similar for the three rotational speeds. However, in the variation of layer numbers, the grain size is increasing as the increasing of layers number.
\end{abstract}

Keywords: Rotational speed; Spin coating; Crystal structur; Grain size

\section{Introduction}

Barium titanate is a material having a ferroelectric property and has a crystal structure of perovskite $\left(\mathrm{ABO}_{3}\right)$. It is usually used as material for the capacitor since it has high dielectric constant [1-4]. The perovskite structure of $\mathrm{BaTiO}_{3}$ has an oxygen ion $\left(\mathrm{O}^{2-}\right)$ in the diagonal of cell unit, Titanium ion $\left(\mathrm{Ti}^{3+}\right)$ in the diagonal space of the cell unit and Barium ion $\left(\mathrm{Ba}^{2+}\right)$ at the top end in each sides of the cell unit [5].

Barium zirconium titanate (BZT) obtained by changing the ions in the place of $\mathrm{B}$ with $\mathrm{Zr}$ in the $\mathrm{BaTiO}_{3}$ compound of the perovskite structure of $\mathrm{ABO}_{3}$ It might be done since the ion of $\mathrm{Zr}^{4+}$ have a size of $0.087 \mathrm{~nm}$ which is larger than the $\mathrm{Ti}^{4+}$ ion, i.e., $0.068 \mathrm{~nm}$. BZT become a prominent material for barium strontium titanate (BST) in the fabrication of ceramic base capacitor since chemically the $\mathrm{Zr}^{4+}$ is more stable than $\mathrm{Ti}^{4+}[6,7]$. The addition of $\mathrm{Zr}$ in the $\mathrm{BaTiO}_{3}$ compound reduce the dielectric loss of barium zirconium titanate (BZT). The application of BZT for microwave technology attracts the attention of the researchers since it has high dielectric constant, low dielectric loss and large tunability [8].

There are several methods for the growing of the BZT thin film such as pulse laser deposition $[9,10]$, sputtering [11] and sol gel method [12-16]. In this paper, we present our results of the growing of BZT thin films using the sol gel method which is prepared with spin coating process. In the spin coating process, the physical parameter which is important in order to yield a good thin film is the rotational speed. Thus, it is necessary to optimize this parameter in order to know the physical characteristic of the BZT thin film. For this purpose, one did several tests, i.e. composition test, crystal structure test and morphological test. The effect of the number of the thin film will also be discussed.

\section{Experiment}

In this research, we use barium acetate, zirconium isopropanol and titanium isopropoxide with the pure of $99 \%, 80 \%$, and $80 \%$, respectively. As a solution, acetic acid and etylene glycol are used. And wafer silicon is used as substrate. Composition of $\mathrm{BZT}$ was $\mathrm{BaZr}_{0,2} \mathrm{Ti}_{0,8} \mathrm{O}_{3}$. The BZT thin film which is growing using sol gel method is prepared with spin coater of CHEMAT technology. The rotational speed of this equipment can be set until $6000 \mathrm{rpm}$. There are three fundamental things that should be taking care in the sol gel method, i.e., the preparation of the solution (chemical process), the growing the thin film with spin coating method and thermal process (annealing). On fabrication of BZT solution, barium acetate and acetic acid was mixed by magnetic stirrer. And then were added successively into the mixture i.e. titanium isopropoxide, zirconium isopropanol and ethylene glycol while were stirred. After that, the solution was heated by hot plate. The BZT solution is made with turbidity of $0.5 \mathrm{M}$. In the spin coating process, we varied spin speed in the value of $2000 \mathrm{rpm}, 3000 \mathrm{rpm}$, and $4000 \mathrm{rpm}$, respectively while the number of layers is taken to be five layers. The number of thin layer is also varied with constant rotational speed of $4000 \mathrm{rpm}$ during 30 seconds. In the annealing process, the temperature is set to $800^{\circ} \mathrm{C}$ for 3 hours. The growth BZT thin film in the Si substrate is then characterized with XRF (X-ray fluoresence) of JEOL to know its composition, XRD (X-ray diffraction) of Bruker D8 Advance with $\lambda \mathrm{Cu}$ $=1,547 \AA$ to find out the crystal structure and SEM (Scanning Electron Microscopy) of Philips to know the morphological structure.

\section{Results and Discussions}

\section{Composition test}

The composition test of the composited material of the BZT, which are barium, zirconium and titanium, is done using the X-Ray Fluorescence. Our results shown that composite material of the BZT are deposited in the Si substrate and it is measured in the percent weight (wt\%). These results are presented in tables 1 and 2 .

*Corresponding author: Yofentina I, Jurusan Fisika FMIPA, Universitas Sebelas Maret, JI. Ir. Sutami 36A Surakarta, Indonesia, E-mail: yopen_2005@yahoo.com

Received August 03, 2012; Accepted September 11, 2012; Published September 18, 2012

Citation: Yofentina I, Viska IV, Hikam M, Bambang S, Alfan M (2012) Optimization of Rotational Speed in the Growing of the Thin Film Using Sol Gel Method which is Prepared with Spin Coating. J Material Sci Eng 1:113. doi:10.4172/2169 0022.1000113

Copyright: (c) 2012 Yofentina I, et al. This is an open-access article distributed under the terms of the Creative Commons Attribution License, which permits unrestricted use, distribution, and reproduction in any medium, provided the original author and source are credited. 
From table 1, it is clear that by increasing the rotational speed then the percent of weight of the composited material of the BZT is decreased. This is because large part of the solution is throwing away from the substrate. In the rotational speed of $4000 \mathrm{rpm}$, the increasing the thin layer numbers makes the composite material is increased as shown in table 2 .

\section{Crystal structure test}

Crystal structure test of the composited BZT thin film is done using the XRD. The resulted diffraction pattern of the BZT thin film is presented in figures 1 and 2 for variation of rotational speed with five layer numbers and for variation of layer numbers with constant rotational speed of $4000 \mathrm{rpm}$, respectively. There are several peaks appears and after it fitted with ICDD database PDF\#36-0019, it is clear that those patterns are for BZT, zirconium titanium oxide and Si substrate.

From figure 1, we see that if the rotational speed is increase then the X-ray intensity is decrease. It is happen since the large part of the solution of the BZT is throwing away from the substrate where it cannot avoid the centrifugal force of the rotational motion. And if the BZT thin film deposited in the substrate is increase then the probability to form a crystal in certain orientation is large. This can be seen also from the results of composition test in table 1 . In our experiment, we also did the measurement for the rotational speed of $1000 \mathrm{rpm}$. However, the solution is forming a gel in the substrate. And when the substrate is heated, the thin film is crack and there is no thin film of BZT is formed. The same situation is also found for the speed of $5000 \mathrm{rpm}$, where the thin film formed is too thin and indeed no thin film formation.

In figure 2, we see that the increasing the number of the layer then the X-ray intensity in a certain orientation is also increased. This indicates that if the number of layers in the Si substrate is increase then the percent weight of the compound materials of BZT is also increased. This can also be seen in the composition test results in table 2. This fact is also indicating that the probability to form a crystal with certain orientation is large.

\section{Morphological test}

The resulted photos from SEM for the BZT thin film are given in figures 3 and 4 . Figure 3 a shows the results for rotational speed of 2000 $\mathrm{rpm}$. And the results for the $3000 \mathrm{rpm}$ and $4000 \mathrm{rpm}$ are shown in figures $3 b$ and $3 c$, respectively. The number of layers is keep fixed at 5 layers. From figure 3, we can see the sharp and homogenous grain with a sharp border between them. In the rotational speed of $2000 \mathrm{rpm}$ and

\begin{tabular}{|l|c|c|c|c|}
\hline \multicolumn{1}{|c|}{ Material } & $\begin{array}{c}\text { Si } \\
\text { Rotational Speed }\end{array}$ & $\begin{array}{c}\text { Ba } \\
(\mathbf{w t} \%)\end{array}$ & $\begin{array}{c}\mathbf{Z r} \\
(\mathbf{w t} \%)\end{array}$ & $\begin{array}{c}\mathrm{Ti} \\
(\mathbf{w t} \%)\end{array}$ \\
\hline $2000 \mathrm{rpm}$ & 80.1517 & 14.0457 & 0.0380 & 5.7646 \\
\hline $3000 \mathrm{rpm}$ & 83.1131 & 12.1608 & 0.0324 & 4.6937 \\
\hline $4000 \mathrm{rpm}$ & 84.8643 & 10.7140 & 0.0250 & 4.3967 \\
\hline
\end{tabular}

Table 1: Composition test of BZT thin film in various rotational speeds with five layers.

\begin{tabular}{|l|c|c|c|c|}
\cline { 1 - 5 } \multicolumn{1}{|c|}{ Material } & $\begin{array}{c}\mathbf{S i} \\
\mathbf{( w t} \%)\end{array}$ & $\begin{array}{c}\mathbf{B a} \\
(\mathbf{w t} \%)\end{array}$ & $\begin{array}{c}\mathbf{Z r} \\
(\mathbf{w t} \%)\end{array}$ & $\begin{array}{c}\mathrm{Ti} \\
(\mathbf{w t} \%)\end{array}$ \\
\hline 5 layers & 84.8643 & 10.7140 & 0.0250 & 4.3967 \\
\hline 10 layers & 61.0206 & 27.2290 & 0.1131 & 11.6372 \\
\hline 15 layers & 40.4091 & 40.8123 & 0.1370 & 18.6416 \\
\hline
\end{tabular}

Table 2: Composition test of BZT thin film in various layers number for rotational speed of $4000 \mathrm{rpm}$.

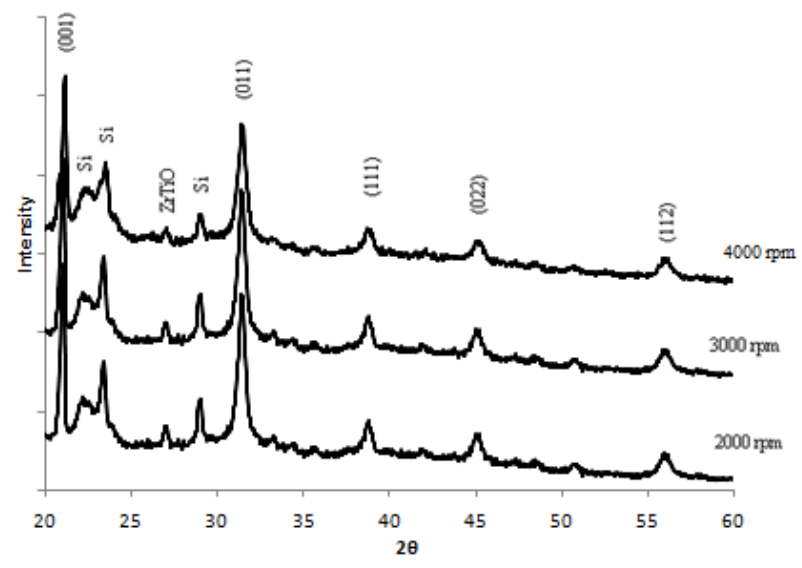

Figure 1: Diffraction pattern of BZT thin film in various rotational speeds.

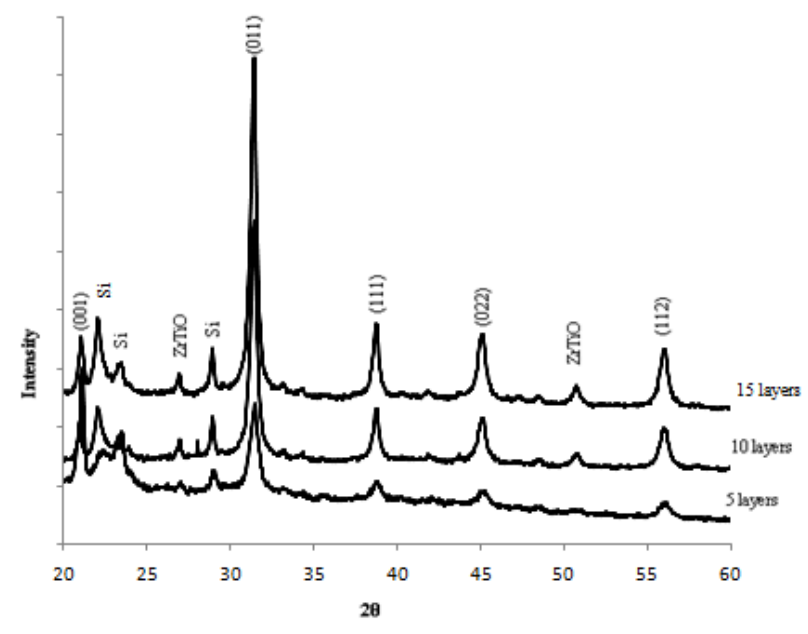

Figure 2: Diffraction pattern of BZT thin film in various layer numbers.

$3000 \mathrm{rpm}$, the grain size is found to be $140 \mathrm{~nm}$. While for the rotational speed of $4000 \mathrm{rpm}$ is around $170 \mathrm{~nm}$. The figure is taken with the zoom of 60.000 times. This probably was caused by increasingly little BZT thin film which has been deposited on substrate. More active grain movement on diffusion process cause more grains diffused become more big grain.

Figure $4 \mathrm{a}$ shows the photos for the five layer numbers of the BZT thin films. And for the 10 and 15 layers are given in figures $4 \mathrm{~b}$ and $4 \mathrm{c}$, respectively. The rotational speed is kept constant at $4000 \mathrm{rpm}$. From figures $4 \mathrm{a}$ and $4 \mathrm{~b}$, we can see the grain clearly. But it is not the case for the 15 layers. The growth of the grain is caused by the diffusion process in the annealing process as well as in the adding of the layer numbers. In the annealing process, the diffusion is taking place in the vertical direction. And in the process of adding the number of layers, it is in the horizontal direction. The grain size of the BZT thin film with five layers is around $170 \mathrm{~nm}$. And for BZT thin film with 10 layers is 400 $\mathrm{nm}$. However, for the thin films with 15 layers, the border between the grains is not clear and it makes difficult to measure the grain size. But it is larger than the size of thin film with 5 and 10 layers.

\section{Conclusion}

We have investigated the effects of the rotational speed in the 
Citation: Yofentina I, Viska IV, Hikam M, Bambang S, Alfan M (2012) Optimization of Rotational Speed in the Growing of the Thin Film Using Sol Gel Method which is Prepared with Spin Coating. J Material Sci Eng 1:113. doi:10.4172/2169-0022.1000113

Page 3 of 3

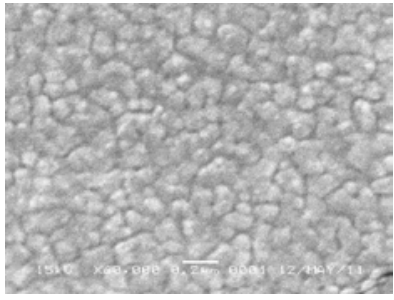

(a)

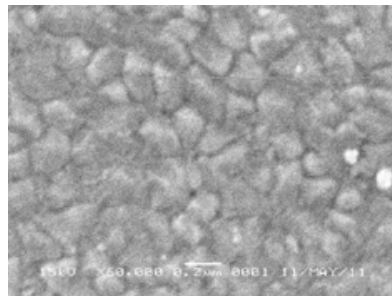

(c)

Figure 3: The resulted photo of SEM for the BZT thin films for the rotational speed of. (a) $2000 \mathrm{rpm}$ (b) $3000 \mathrm{rpm} \quad$ (c) $4000 \mathrm{rpm}$

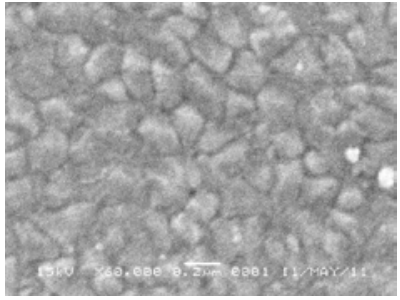

(a)

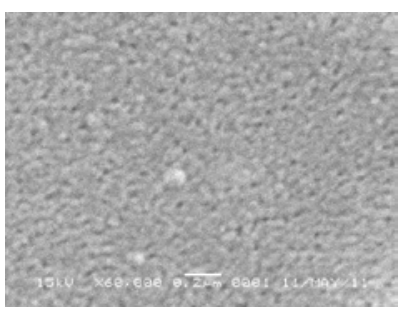

(c)

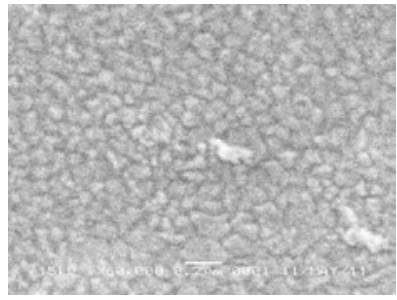

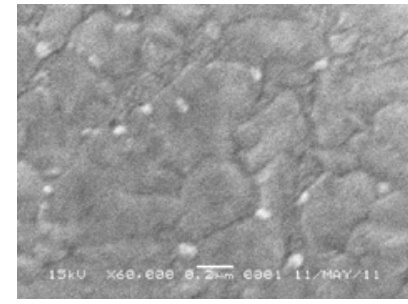

(b)
Figure 4: The resulted photo of SEM for the BZT thin film with $\begin{array}{llll}\text { (a) } 5 \text { layers } & \text { (b) } 10 \text { layers } & \text { (c) } 15 \text { layers. }\end{array}$

spin coating process for the growing of the BZT thin film. It is found with the increasing of the rotational speed, the deposited material in the $\mathrm{Si}$ substrate is decreased. As a result, the X-ray intensity in certain orientation is also decreased. It indicates that the probability to form the crystal in a certain orientation is influenced by deposited material in the Si substrate. The measured grains size of the BZT thin film almost similar for the three rotational speeds used in this experiment. However, in the variation of layer numbers, the grain size is not similar but it is increasing as the increasing of layers number. This is caused by the diffusion process happen between the grain in the horizontal and the vertical directions.

\section{Acknowledgment}

This research is supported by Incentive Grant for Applied Research Project 2011 from Ministry of Research and Technology, the Republic of Indonesia.

\section{References}

1. Gao C, Zhai J, Yao X (2008) Effect of seed layers on dielectric properties of $\mathrm{Ba}\left(\mathrm{Zr}_{0.3} \mathrm{Ti}_{0.7}\right) \mathrm{O}_{3}$ thin films. J Electroceram 21: 653-656.

2. Li W, Xu Z, Chu R, Fu P, Hao J (2009) Structure and electrical properties of $\mathrm{BaTiO}_{3}$ prepared by sol-gel process. J Alloys Compd 482: 137-140.

3. Kavian R, Saidi A (2009) Sol-gel derived $\mathrm{BaTiO}_{3}$ nanopowders. J Alloys Compd 468: 528-532.

4. Maie H, Lee $\mathrm{BI}$ (2009) The hydroxyl concentration and the dielectric properties of barium titanate nano-powder synthesized by water-based ambient condition sol process. J Mater Sci: Mater Electronics 20: 619-627.

5. Jona F, Shirane G (1993) Ferroelectric crystals. Dover Publications, New York USA.

6. Jiwei Z, Xi Y, Liangying Z, Bo S (2004) Dielectric nonlinear characteristics of $\mathrm{Ba}\left(\mathrm{Zr}_{0.35} \mathrm{Ti}_{0.65}\right) \mathrm{O}_{3}$ thin films grown by a sol-gel process. Appl Phys Lett 84: 3136 3138.

7. Cavalcante LS, Anicete-Santos M, Pontes FM, Souza IA, Santos LPS, et al (2007) Effect of annealing time on morphological characteristics of $\mathrm{Ba}(\mathrm{Zr}, \mathrm{Ti}) \mathrm{O}_{3}$ thin films. J Alloys Compd 437: 269-273.

8. Wang DY, Yun P, Wang Y, Chan HLW, Choy CL (2009) Influence of Oxygen Partial Pressure on the Structural and Dielectric Properties of $\mathrm{Ba}\left(\mathrm{Zr}_{0.3} \mathrm{Ti}_{0.7}\right) \mathrm{O}_{3}$ Thin Films Grown on $\left(\mathrm{LAALO}_{3}\right)_{03}\left(\mathrm{SR}_{2} \mathrm{ALTAO}_{6}\right)_{0,35}(001)$ Using Pulsed Laser Deposition. Thin Solid Films 517: 2092-2098.

9. Halder S, Bhattacharyya S, Krupanidhi SB (2002) Electrical characterization of $\mathrm{Ba}\left(\mathrm{Zr}_{0.1} \mathrm{Ti}_{0.9}\right) \mathrm{O}_{3}$ thin films grown by pulsed laser ablation technique. Mater Sci Eng: B 95: 124-130.

10. Yan-ping J, Xin-gui T, Qiu-xiang L, Tie-dong C, Yi-chun Z (2007) XPS study of BZT thin film deposited on $\mathrm{Pt} / \mathrm{Ti} / \mathrm{SiO}_{2} / \mathrm{Si}$ substrate by pulsed laser deposition. Trans Nonferrous Met Soc China 17: s862-s865

11. Moo-Chin W, Chen CY, His CS, Wu NC (2003) Influence of deposition parameters on the dielectric properties of if magnetron sputtered $\mathrm{Ba}\left(\mathrm{Zr}_{x} \mathrm{Ti}_{1-x}\right) \mathrm{O}_{3}$ thin films. J Eur Ceram Soc 23: 2307-2314.

12. Zhai J, Hu D, Yao X, Xu Z, Chen $\mathrm{H}$ (2006) Preparation and tunability properties of $\mathrm{Ba}\left(\mathrm{Zr}_{\mathrm{x}} \mathrm{Ti}_{1-\mathrm{x}}\right) \mathrm{O}_{3}$ thin films grown by asol-gel process. J Eur Ceram Soc 26 1917-1920.

13. Kumar M, Garg A, Kumar R, Bhatnagar MC (2008) Structural, dielectric and ferroelectric study of $\mathrm{Ba}_{0.9} \mathrm{Sr}_{0.1} \mathrm{Zr}_{x} \mathrm{Ti}_{1-\mathrm{x}} \mathrm{O}_{3}$ ceramics prepared by the sol-gel method. Physica B Condens Matter 403: 1819- 1823.

14. Gao C, Zhai J, Yao X (2008) Effect of seed layers on dielectric properties of $\mathrm{Ba}\left(\mathrm{Zr}_{0.3} \mathrm{Ti}_{0.7}\right) \mathrm{O}_{3}$ thin films. J Electroceram 21: 653-656.

15. Halder S, Gerber P, Schneller T, Waser R (2005) Electromechanical properties of $\mathrm{Ba}\left(\mathrm{Ti}_{1-\mathrm{x}} \mathrm{Zr}_{\mathrm{x}}\right) \mathrm{O}_{3}$ thin films. Appl Phys A Mater Sci Process 81: 11-13.

16. Halder S, Schneller T, Bottger U, Waser R (2005) Fabrication and electrical characterisation of $\mathrm{Zr}$-substituted $\mathrm{BaTiO}_{3}$ thin films. Appl Phys A Mater Sci Process 81: 25-29. 